Q Nueva Etinexaxio Revista Digital de OFilosofia ISSN 1850-3578 2013 - Vol. 8 - Número VIII - Resistencia, Chaco, Argentina. Pp. 39 - 57

\title{
Nihilismo y diferencia de fuerzas: la interpretación deleuziana de la filosofía de Nietzsche como modo alternativo al de la metafísica occidental para comprender la realidad
}

\author{
Juan Pablo E. Esperón ${ }^{1}$ \\ Universidad del Salvador. Unlam, Ancba, CONICET (Argentina)
}

Recibido: 10/07/2013

Aceptado: 23/07/2013

\section{Resumen}

En el presente artículo nos proponemos delimitar la cuestión del nihilismo que asola a la tradición occidental de pensamiento a partir de la sentencia de Nietzsche "Dios ha muerto" para mostrar luego como Deleuze, interpretando la filosofía nietzscheana, postula una filosofía de la inmanencia y la diferencia de fuerzas como alternativa a un modo de pensar nihilista, reelaborando nociones claves de la filosofía nietzscheana como fuerza, devenir, voluntad, eterno retorno y diferencia.

Palabras clave: filosofía, nihilismo, fuerza, diferencia.

\section{Summary}

In this paper we propose to define the question of nihilism that plagues the Western tradition of thought from Nietzsche's statement "God is dead" to show then as Deleuze also supported in Nietzschean philosophy, posits a philosophy of immanence and the difference of forces as an alternative to a mindset nihilist reworking key concepts as force Nietzschean philosophy as a force, becoming, will, eternal return and difference.

\footnotetext{
${ }^{1}$ Juan Pablo E. Esperón es doctor, profesor e investigador de filosofía por la universidad del Salvador. Profesor e investigador de la universidad nacional de la Matanza en Buenos Aires, Argentina y de la academia nacional de ciencias de Buenos Aires. Es miembro del CONICET y de la sociedad iberoamericana de estudios heideggerianos. Es editor responsable de la revista de filosofía Nuevo pensamiento dependiente del instituto de investigaciones filosóficas de la Universidad del salvador, área San Miguel en Bs. As. E-mail: jpesperon@hotmail.com. Ha publicado numerosos artículos y libros respecto de la filosofía de Nietzsche, Heidegger y Deleuze.
} 
Q Nueva Etinexaxio Revista Digital de OFilosofia ISSN 1850-3578 2013 - Vol. 8 - Número VIII - Resistencia, Chaco, Argentina. Pp. 39 - 57

Keywords: philosophy, nihilism, power, difference 
Pverea Etinexaxio Revista Digital de OFilosofla ISSN 1850-3578 2013 - Vol. 8 - Número VIII - Resistencia, Chaco, Argentina. Pp. 39 - 57

\section{El anuncio nietzscheano de la muerte de dios como delimitación y destrucción de la metafísica.}

El pensar mismo se presenta en Nietzsche orientado hacia una destrucción total de las categorías metafísicas, pero también como apertura de caminos que muestran un nuevo modo de hacer filosofía para habitar y relacionarse con el mundo. La metafísica, que Nietzsche combate, no puede ser superada a través de una simple inversión, que significa repetir su lógica en otros términos, ni por la destrucción absoluta de la disyunción, que significa la afirmación de un monismo que supone la ausencia de libertad. Nietzsche lleva adelante tal destrucción con la figura del filósofo topo, cuya tarea consiste en realizar un análisis genealógico de la cultura, socavando sus fundamentos y sus presupuestos últimos con el objeto de hacer estallar las bases de las categorías que rigen el pensar occidental. Fundamento, bien, verdad, dios, ciencia y razón son algunos de los conceptos que somete a tal destrucción. Como sostiene Cragnolini, su tarea consiste en llevar estos conceptos al límite del pensamiento $y$, de este modo, mostrar qué significan en realidad, y allí, en el límite, observar sus grietas y fisuras para lograr movernos por medio de ellos. En este sentido, como afirmamos arriba, la filosofía de Nietzsche no apunta a una simple inversión ni a la destrucción de las oposiciones metafísicas en pos de un monismo, sino que su tarea puede ser caracterizada como subversiva. Así, pues, Nietzsche, socava las bases mismas del sistema del pensamiento metafísico, destruye su fundamento: la arkhé, en torno al cual se ha constituido el pensamiento y la cultura occidental en su totalidad. De este modo, queda en suspenso todo par de contrarios de la lógica de oposición y se des-oculta lo que verdaderamente hay que pensar: el entre, el medio de las oposiciones, ${ }^{2}$ esto es, la diferencia.

Como es sabido, la vida intelectual de Nietzsche se ha desarrollado en la segunda mitad del siglo XIX, sin embargo pudo pensar su tiempo histórico anunciando y problematizando lo que asola a nuestro siglo. En este sentido se percibe en Nietzsche cierto tono profético anticipando la historia venidera de occidente desde una profunda comprensión de aquello que ya estaba germinando en el siglo XIX, el advenimiento y la consumación del nihilismo.

¿Qué entiende Nietzsche por Nihilismo?, ¿cuál es su esencia?, ¿por qué nuestra contemporánea historia se caracteriza por ser nihilista? Escuchemos las respuestas que da Nietzsche, Nihilismo: significa que los valores supremos se han desvalorizado, por ello hay que poner en entredicho el valor mismo de los valores. ${ }^{3}$ Ahora bien, esto muestra, como afirmamos arriba, que la metafísica y la propia historia de occidente están constituidas sobre la

\footnotetext{
${ }^{2}$ Cfr. CRAGNOLINI, Mónica, Derrida, un pensador del resto, La Cebra, Bs. As., 2007, p. 14 ss.

${ }^{3}$ Cfr. NIETZSCHE, Friedrich W., La genealogía de la moral, Alianza, Madrid, 1972, p. 23.
} 
Q Nueva Etinexaxio Revista Digital de OFilosofia ISSN 1850-3578 2013 - Vol. 8 - Número VIII - Resistencia, Chaco, Argentina. Pp. 39 - 57

base del nihilismo. En este sentido, el combate nietzscheano ha de ser muy difícil y conllevará un enorme esfuerzo. Es por esto que Nietzsche utiliza ciertas armas para planear su estrategia de lucha contra la metafísica y así destruir su estructura disyuntiva que supone, a su vez, la destrucción de la historia occidental. Esta es la filosofía del martillo. Destruir a golpes de martillo todas las categorías metafísicas comenzando con aquella unidad dadora de sentido de todo lo que es: el dios de la metafísica. Así, puede caracterizar, Nietzsche, a la historia occidental como nihilista, bajo la sentencia "Dios ha muerto" que indica la pérdida del sentido y valor del mundo trascendente, unificado en dios como arkhé, unidad fundamentadora, rectora y unificadora de todos los ámbitos de la realidad, del conocimiento y la moral. Con la noción de nihilismo Nietzsche afirma, entonces, que el valor de los valores - unificados en dios como lo uno, la verdad, la justicia, el ser, las ideas- se ha desvalorizado, no nos orientan a nada, no ordenan nada. En esto consiste, asimismo, su labor genealógica; mostrar que el origen de los valores occidentales que se presentan como eternos, son, en realidad, producto de una voluntad débil y decadente, y por lo tanto, insignificantes. Nietzsche pone el acento en que el hombre mismo fue quien ha puesto ciertos valores, ciertos fundamentos, que fueron reverenciados en la historia occidental, y que se ha olvidado semejante hecho, quedando ubicados en un mundo trascendente e inaccesible, donde el hombre mismo termina sometiéndose voluntariamente a ellos, convirtiéndolos, así, en principios determinadores de maneras y pautas incuestionables de acción y pensamiento.

Resumiendo, podemos afirmar que el nihilismo nietzscheano en cuanto desvalorización de los valores supremos, muestra la negación y destrucción toda arkhé que permita unificar ontoteo-lógicamente ${ }^{4}$ el flujo del devenir-multiplicidad del ser; esto es la destrucción del primer principio, de dios, del ser como fundamento del ente, del bien, de la verdad y el optimismo tecno-científico.

Nietzsche señala dos tipos de nihilismo: por un lado, el nihilismo activo, aquel según el cual tiene la fuerza para destruir los valores que han perdido sentido, pero todavía no tiene la fuerza para imponer y crear nuevos valores; pero, por otro lado, hay un nihilismo más peligroso, el nihilismo pasivo, que muestra por todas partes los signos de debilidad producto de la cultura occidental. Aquí, la fuerza propia del espíritu está cansada, agotada. Así, los valores que tenían crédito pierden su lugar, se consideran inadecuados, pero no hay fuerza

\footnotetext{
${ }^{4}$ La metafísica es aquella disciplina que teoriza sobre el ente en cuanto ente, en busca de su estructura general -ontología-, y teoría del ente supremo del cual dependen todos los demás entes -teología. Heidegger llama "onto-teo-logía" a la forma de pensar, que desde Platón a la actualidad, se despliega como teoría general del ser del ente y como teoría del ente supremo, dado que se ha olvidado al ser mismo, a favor del ser como fundamento del ente.
} 
para destruirlos, por lo tanto vuelven a aparecer con nuevos disfraces - religiosos, morales, epistémicos, estéticos-, cuya consecuencia es la decadencia en la cual está sumergida la cultura actual.

Adentrémonos estrictamente en la esencia del nihilismo que en sentido amplio Nietzsche expresó con la sentencia "Dios ha muerto" anunciado en el pasaje de La Ciencia Jovial que lleva el título de "El Hombre frenético" ${ }^{5}$. Este pasaje a dado lugar a ciertos equívocos (por ejemplo, que las afirmaciones nietzscheanas llevan a un mero ateísmo), ${ }^{6}$ debido a que no

\begin{abstract}
5 “¿No habéis oído hablar de que aquel hombre frenético que en la claridad del mediodía prendió una lámpara, corrió al mercado y gritaba sin cesar: “iBusco a Dios, busco a Dios!” Puesto que allí estaban reunidos muchos que precisamente no creían en Dios, provocó una gran carcajada. "¿Es que se ha perdido?", dijo uno. "¿Se ha extraviado como un niño?" dijo otro. "¿O es que se mantiene escondido? ¿Tiene temor de nosotros? ¿Se ha embarcado en un navío? ¿Ha emigrado?" - así gritaban y reían confusamente. El hombre frenético salto en medio de ellos y los traspasó con su mirada. "¿A dónde ha ido Dios?", gritó, "iyo os lo voy a decir! iNosotros lo hemos matado - vosotros y yo! iTodos nosotros somos sus asesinos! ¿Pero cómo hemos hecho esto? ¿Cómo fuimos capaces de beber el mar? ¿Quién nos dio la esponja para borrar todo el horizonte? ¿Qué hicimos cuando desencadenamos esta tierra de su sol? ¿Hacia dónde se mueve ahora? ¿Hacia dónde nos movemos nosotros? ¿Lejos de todos los soles? ¿No caemos continuamente? ¿Y hacia atrás, hacia los lados, hacia delante, hacia todos los lados? ¿Hay aún un arriba y un abajo? ¿No erramos como a través de una nada infinita? ¿No nos sofoca el espacio vacío? ¿No se ha vuelto todo más frío? ¿No lleva continuamente la noche y más noche? ¿No habrán de ser encendidas lámparas a mediodía? ¿No escuchamos aún nada del ruido de los sepultureros que entierran a Dios? ¿No olemos aún nada de la descomposición divina? -también los dioses se descomponen. ¡Dios ha muerto! ¡Dios permanece muerto! ¡Y nosotros lo hemos matado! ¿Cómo nos consolamos los asesinos de todos los asesinos? Lo más sagrado y más poderoso que poseía todo el mundo, sangra bajo nuestros cuchillos- ¿quién nos lavará esta sangre? ¿Con qué agua podremos limpiarnos? ¿Qué fiestas expiatorias, qué juegos sagrados tendremos que inventar? ¿No es la grandeza de este hecho demasiado grande para nosotros? ¿No hemos de convertirnos nosotros mismos en dioses, sólo para aparecer dignos ante ellos? ¡Nunca hubo un hecho más grande- y quienquiera nazca después de nosotros, pertenece por la voluntad de este hecho a una historia más alta que todas las historias habidas hasta ahora!".

Aquí calló el hombre frenético y miró nuevamente a sus oyentes: también estos callaron y lo miraron extrañados. Finalmente lanzó él su lámpara al suelo, que saltó en pedazos y se apagó. "Llego muy temprano", dijo luego, todavía no estoy a tiempo. Este acontecimiento inaudito aún está en camino y peregrina- aún no se ha adentrado hasta los oídos de los hombres. El rayo y el trueno necesitan tiempo, la luz de las estrellas necesita tiempo, los hechos necesitan tiempo, aún después de que han sido hechos, para ser vistos y escuchados. Este hecho les es todavía más lejano que la más lejana estrella -iy sin embargo, ellos mismos lo han hecho!".
\end{abstract}

Se cuenta que aquel mismo día el hombre frenético irrumpió en diferentes iglesias y entonó su Requiem aeternam (Descanso eterno para Dios). Sacado de ellas e impedido de hablar, sólo respondió una y otra vez: “¿Qué son aún estas iglesias, si no son las criptas y mausoleos de Dios?". NIETZSCHE, Friedrich W., La ciencia Jovial, Monte Avila, Caracas, 1990, p. 116-118.

${ }^{6}$ Recordemos que en la configuración de la metafísica como onto-teo-logía el movimiento resulta no explicado y, por ende, negado. Asimismo, esto ocurre a lo largo de toda la historia de la metafísica porque el movimiento no deja apresarse en un horizonte categorial estable; así el devenir deja de ser pensable dentro de la lógica metafísica de la identidad; es decir, no permite ser pensado en esas condiciones. Esto ocurre porque Aristóteles se pregunta ¿qué determina al ser en potencia pasar al acto en vez de no pasar? La respuesta es la afirmación de que hay un primer principio idéntico a sí mismo que no es producido, sino que es siempre en acto, aquí queda fundada la metafísica como onto-teología. La conclusión de ello es que en el principio no hay caos sino algo determinado, una causa siempre en acto que impulsa el cambio. La sombra sucede después de la luz; esta luz no es sólo la luz de la 


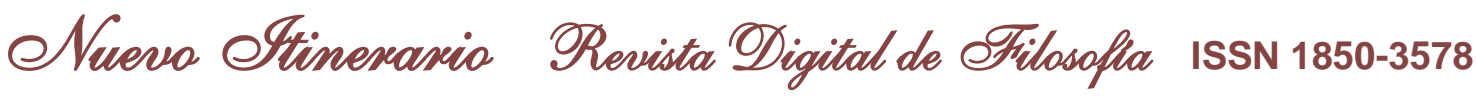
2013 - Vol. 8 - Número VIII - Resistencia, Chaco, Argentina. Pp. 39 - 57

podemos comprender que quiere significar Nietzsche en él si no se tiene en cuenta la temática que gira en torno al problema del nihilismo.

Pero la sentencia "Dios ha muerto", nos indica (en relación con la cuestión del nihilismo), por un lado, la destrucción del mundo suprasensible (platónico) de las ideas eternas e incuestionables, pero por otro lado, significa también, la destrucción del modo de pensamiento tecno-científico como único modo de pensar viable para el hombre; por ende, esto conlleva a la destrucción de la lógica metafísica de oposición disyuntiva. La muerte de dios muestra la consumación y el final del pensamiento dicotómico regido por la lógica de la identidad y el principio de no contradicción.

Heidegger, por su parte, ya da cuenta de la desdivinización del mundo en su ensayo de 1938 titulado "La época de la imagen del mundo"7, como uno de los rasgos característicos de la época moderna; refiriéndose con aquella noción, no a la negación de dios, sino al modo como el cristianismo se ha configurado en una ideología, dando lugar a la huida de lo divino. Luego, interpretando el pasaje de Nietzsche citado arriba, en su ensayo titulado "La frase de Nietzsche "Dios ha Muerto", sostiene que esta sentencia designa el destino de dos milenios de historia occidental (el nihilismo), ${ }^{8}$ al tiempo que nos advierte que con la muerte de dios, Nietzsche, claramente refiere al dios cristiano pero como símbolo para designar la pérdida del valor del mundo suprasensible de la metafísica y su constitución onto-teo-lógica. De este modo, el dios muerto designa que el valor de los valores que sostuvieron y ordenaron la historia y la cultura occidental ya no valen, o lo que es lo mismo, no tienen fuerza, no mueven a nada. ${ }^{9}$ Esto muestra, que la metafísica ha llegado a su consumación lo que significa, por un lado, no que haya acabado o finalizado, sino que ha desplegado todas sus posibilidades de dominio; por otro lado, al desplegar todas sus posibilidades, la metafísica muestra sus propios límites, lo cual nos coloca, de algún modo, fuera de ella. Para Heidegger, el nihilismo es el movimiento fundamental de la historia de occidente que en la época de la técnica moderna ha de

ciencia sino también la de la religión, la del lógos "en arkhé ho lógos" (Juan I, 1: "In principio erat vebum"). De este modo, el horizonte epistémico y el religioso son uno e idénticos en su constitución occidental. No hay más misterio, ni espacio para lo divino en occidente, ni angustia, sino seguridad epistémica y salvación. "La lógica ha derrotado al pesimismo. Pero sólo porque ha renunciado al devenir por el ser, al movimiento por la quietud. A la vida por la no-vida" (VITIELLO, Vincenzo, "Federico Nietzsche y el nacimiento de la tragedia". En Secularización y nihilismo. Bs. As.: Jorge Baudino-UNSAM., p. 83). Es precisamente contra esta tradición del primado de la luz, de la certeza, del optimismo científico, contra lo que Nietzsche embate, denunciando que tanto el saber, la verdad como la religión y la ciencia son también perecederos.

${ }^{7}$ Cfr. HEIDEGGER, Martin, "La época de la imagen del mundo", en Caminos de Bosque, Alianza, 1995.

${ }^{8}$ Cfr. HEIDEGGER, Martin, "La frase de Nietzsche: Dios ha Muerto", en Caminos de Bosque, Alianza, 1995, p. 160.

${ }^{9}$ Cfr. HEIDEGGER, Martin, “La frase de Nietzsche: Dios ha Muerto”, p. 162. 
Q Nueva Etinexaxio Revista Digital de OFilosofia ISSN 1850-3578 2013 - Vol. 8 - Número VIII - Resistencia, Chaco, Argentina. Pp. 39 - 57

consumarse, y que muestra, en todos los ámbitos de la realidad, sus consecuencias devastadoras. El discurso del hombre loco, que no es un hombre ateo como se suele interpretar, sino que mienta un hombre religioso en búsqueda de la divinidad (v. g. "el hombre loco grita incesantemente: busco a dios, busco a dios ${ }^{\prime 10}$ ), nos advierte, por un lado, que el nihilismo ha llegado y ha penetrado en nuestra cultura, pero por otro lado, que aún no hemos de tomar conciencia de semejante situación y decadencia que conlleva semejante advenimiento ( $v$. g. los mercaderes que creen que descreyendo de toda religión se ha superado el nihilismo). Ello muestra que seguimos pensando, aún, de acuerdo a la lógica metafísica.

II. Más allá de la metafísica. La recepción deleuziana de la filosofía de Nietzsche: una ontología de la diferencia de fuerzas.

Deleuze sostiene que la filosofía debe entenderse como una crítica positiva en el sentido de que ella implica creatividad afirmando que "el problema crítico es el valor de los valores, la valoración de la que procede su valor, o sea, el problema de su creación" ${ }^{11}$ Este problema solo puede ser evaluado a partir del elemento diferencial (la voluntad de poder): elemento determinante de toda valoración dado que muestra la cualidad de la fuerza, i. e., activoreactivo, siendo a la vez, elemento crítico y creador. El problema crítico es doble: el valor de los valores (el sentido) y la valoración de la que procede su valor (la voluntad), es decir, los modos de existencia, diferenciales, jerárquicos, creadores de valores (lo alto y lo bajo, lo noble y lo vil).

\begin{abstract}
"así entendida, la crítica es al mismo tiempo lo más positivo. El elemento diferencial no es crítica del valor de los valores, sin ser también el elemento positivo de una creación. Por este motivo la crítica no ha sido jamás concebida por Nietzsche como una reacción, sino como una acción. Nietzsche opone la actividad de la crítica a la venganza, al rencor o al resentimiento". ${ }^{12}$
\end{abstract}

Este doble movimiento de la crítica deviene así en genealogía activa, positiva, creativa. Pero a continuación afirma Deleuze:

\footnotetext{
${ }^{10}$ NIETZSCHE, Friedrich W., La ciencia Jovial, Monte Avila, Caracas, 1990, p. 117.

11 DELEUZE, GILLES, Nietzsche et la philosophíe, París: PUF, 1962. Edición hispana: Deleuze, Gilles, Nietzsche y la filosofía, trad. Carmen Artal, Barcelona: Anagrama, 1971. En adelante todas las citas se harán de la edición hispana aquí citada con la sigla NP. En este caso DELEUZE, GILLES, NP, p. 7.

${ }^{12}$ DELEUZE, GILLES, NP, p. 9.
} 


\begin{abstract}
"Nunca encontraremos el sentido de algo (fenómeno humano, biológico o incluso
físico), si no sabemos cuál es la fuerza que se apropia de la cosa, que la explota, que se apodera de ella o se expresa en ella. Un fenómeno no es una apariencia ni tampoco una aparición, sino un signo, un síntoma que encuentra su sentido en una fuerza actual". ${ }^{13}$
\end{abstract}

Así como el desarrollo del problema del valor supone un nuevo "método" (genealogía), así también el desarrollo del problema del sentido requiere de una teoría de las fuerzas. La historia de una cosa, cualquiera que esta sea, supone una sucesión de fuerzas que se apoderan de ella, la constituyen y coexisten en ella para apoderársela. Así, un mismo fenómeno cambia su sentido de acuerdo a la fuerza que se apodere de él. Pero siempre hay una pluralidad de sentido, una constelación de sentido. El sentido es una noción compleja: en primer lugar implica siempre relaciones plurales. Una constelación es un sistema abierto. En un sistema cerrado hay leyes que gobiernan el movimiento y las relaciones entre los elementos, aun cuando el sistema sea dinámico y variable. En una constelación eso no es posible, porque no se puede abarcar la totalidad y su conocimiento es siempre provisorio. La constelación incluye tanto las relaciones temporales como las espaciales. Así, la historia es la variación de esos sentidos en estas relaciones y se puede apreciar haciendo una hermenéutica de las fuerzas que en cada momento se apropian de un fenómeno o de un ser y que le confieren un sentido actual o que le fueron dando diferentes sentidos en el tiempo. En definitiva, todo acontecimiento $^{14}$ tiene múltiples sentidos. Además, estos sentidos nunca son "eternos" o "permanentes", sino que son siempre "inestables". Hay que pensar en una dinámica de las fuerzas. No se trata de un sistema cerrado de fuerzas, sino un sistema inestable. Al dominar un

\footnotetext{
${ }^{13}$ DELEUZE, GILLES, NP, p. 10.

${ }^{14}$ El concepto de "acontecimiento" es central en el pensamiento deleuziano. Se opone a la concepción cristiana y dialéctica de la historia, que considera a la historia sujeta a una legalidad necesaria y a una teleología que encamina los hechos hacia un fin único en el que se consuma todo el desarrollo. El concepto de "acontecimiento" supone una relación contingente de las relaciones de fuerza en la historia. ¿Cómo se produce un acontecimiento si no es como resultado de un movimiento dialéctico? Cuando se habla de "acontecimiento" hay que pensar en una multiplicidad de fuerzas (aunque los tipos de fuerzas puedan reducirse a lo alto y lo bajo). Hay acontecimientos que resultan de una conjunción de fuerzas activas y creativas, como en Mayo del '68. Los acontecimientos de este tipo no se caracterizan por su duración sino por los efectos múltiples que generan. (En un reportaje a Mario Benedetti divulgado en un programa sobre este autor uruguayo en Canal Encuentro, decía que para su generación, el acontecimiento había sido la Revolución Cubana y no Mayo del '68, que no había tenido consecuencias significativas para los sudamericanos). Los grandes acontecimientos no están precedidos por causas que permitan preverlos con anterioridad, sino que pueden resultar de situaciones mínimas, banales o imperceptibles, lo cual puede vincularse con el "efecto mariposa".
} 
Q Nueva Etinexaxio Revista Digital de OFilosofia ISSN 1850-3578 2013 - Vol. 8 - Número VIII - Resistencia, Chaco, Argentina. Pp. 39 - 57

fenómeno, la fuerza le da un sentido, le da una dirección. El significado más simple de "sentido" es "dirección". Deleuze, a partir de la filosofía de Nietzsche, está desarrollando una teoría general de la fuerza, que no se restringe a las relaciones humanas ni sociales, tampoco a lo orgánico, vital o biológico. Las fuerzas son relaciones entre fenómenos. Las relaciones entre fuerzas ni siquiera suponen un "sujeto". Aquí Nietzsche se muestra como un heredero de la tradición iluminista: Kant ya había impreso el giro al pensamiento por el cual se deja de poner el acento en el conocimiento para centralizar en la acción, en la moral. Después de él, la primacía de la acción se desarrollará cada vez más con Fichte, Schelling, Hegel, la filosofía del idealismo alemán, Marx y la filosofía de la praxis. Nietzsche es heredero de esta tradición que deja de pensar en términos de cosas o de esencias para pensar en términos de acción, de fuerzas (o, como la va a llamar más adelante: de voluntad). En síntesis, por un lado, el sentido es siempre múltiple porque está constituido por una pluralidad de fuerzas que lo definen pero también diferentes respecto a otras fuerzas; por otro lado, el sentido nunca es absoluto sino que cambia cuando cambian las fuerzas que se apoderan de él.

Retomemos el otro problema de la genealogía: el valor, Deleuze afirma que "la genealogía no solo interpreta sino también valora" ${ }^{15}$

\begin{abstract}
“Cualquier fuerza se halla pues en una relación esencial con otra fuerza. El ser de la fuerza es el plural; sería completamente absurdo pensar la fuerza en singular. Una fuerza es dominación, pero también objeto sobre el que se ejerce una dominación. Una pluralidad de fuerzas actuando y sufriendo a distancia, siendo la distancia el elemento diferencial comprendido en cada fuerza y gracias al cual cada una se relaciona con las demás". ${ }^{16}$
\end{abstract}

El elemento diferencial (la voluntad que es una fuerza relacionada con otra fuerza) permite evaluar y caracterizar la diferencia en el origen como la cualidad de la vida y sólo hay dos tipos de vida: lo afirmativo y lo negativo, lo alto y lo bajo, la acción y la reacción. La pregunta que supone el elemento diferencial con respecto a las fuerzas es: ¿es activa o es reactiva? ¿es afirmativa o es negativa? ¿es alta o es baja? La diferencia implica siempre actividad (o reactividad), movimiento (o resistencia), relación (mando u obediencia), generación (creación o decadencia). Porque el problema de la filosofía como crítica genealógica es la relación que se establece entre una voluntad que ordena y otra que obedece.

\footnotetext{
${ }^{15}$ DELEUZE, GILLES, NP, p. 14.

${ }^{16}$ DELEUZE, GILLES, NP, p. 14.
} 


\begin{abstract}
"Que cualquier fuerza se relaciona con otra, sea para obedecer sea para mandar, he aquí lo que nos encamina hacia el origen: el origen es la diferencia en el origen, la diferencia en el origen es la jerarquía, es decir la relación de una fuerza dominante con una fuerza dominada, de una voluntad obedecida con una voluntad obediente". ${ }^{17}$
\end{abstract}

Por ello afirma Deleuze que el verdadero problema de la genealogía es la jerarquía, ${ }^{18}$ y ella es inseparable de la diferencia y del origen. La genealogía tiene como tarea el problema del sentido y del valor y su mutua relación dado que "el sentido de una cosa es la relación entre esta cosa y la fuerza que la posee, el valor de una cosa es la jerarquía de las fuerzas que se expresan en la cosa en tanto que fenómeno complejo" ${ }^{19}$

La voluntad de poder es el elemento diferencial y genealógico de la fuerza, es decir, ella determina la relación de una fuerza con otra fuerza. Por ello la voluntad de poder nunca se puede separar de la fuerza. Tengamos en cuenta que la voluntad de poder no es la misma fuerza, hay que diferenciar la voluntad de la fuerza, pero la voluntad de poder no es exterior a la fuerza es la fuerza misma, su afectividad. Esto podemos aclararlo al preguntar ¿quién quiere? No se puede responder la fuerza, porque no es la fuerza quien quiere, sino la voluntad es quien quiere $y$, ello, no pude ser alienado ni delegado. Sin el elemento interno de la voluntad toda fuerza sería indeterminada. "La voluntad de poder, pues, se suma a la fuerza, pero como elemento diferencial y genético, como elemento interno de su producción" ${ }^{20}$ Deleuze también afirma que la voluntad de poder no es el ser ni tampoco el devenir. "La voluntad de poder se manifiesta como la sensibilidad de la fuerza; el elemento diferencial de las fuerzas se manifiesta como su sensibilidad diferencial" ${ }^{21}$ Es decir es el poder de afectar y ser afectado.

\footnotetext{
${ }^{17}$ DELEUZE, GILLES, NP, p. 16.

${ }^{18}$ Deleuze afirma que "la jerarquía tiene dos sentidos en Nietzsche. Significa, en primer lugar, la diferencia de las fuerzas activas y reactivas, la superioridad de las fuerzas activas sobre las reactivas (...) Pero jerarquía designa también el triunfo de las fuerzas reactivas, el contagio de las fuerzas reactivas y la organización compleja que viene detrás, donde los débiles han vencido, donde los fuertes son contaminados, donde el esclavo que no ha dejado de ser esclavo prevalece sobre un señor que ha dejado de serlo: el reino de la ley y de la virtud. Y en este segundo sentido, la moral y la religión aún son teorías de la jerarquía". (DELEUZE, GILLES, NP, p. 88).

${ }^{19}$ DELEUZE, GILLES, NP, p. 16.

${ }^{20}$ DELEUZE, GILLES, NP, p. 75.

${ }^{21}$ DELEUZE, GILLES, NP, p. 91.
} 
QNueva Etinexaxia Revista Digital de OFilosofia ISSN 1850-3578 2013 - Vol. 8 - Número VIII - Resistencia, Chaco, Argentina. Pp. 39 - 57

Deleuze se pregunta entonces:

\begin{abstract}
“¿Qué es el cuerpo? Solemos definirlo diciendo que es un campo de fuerzas, un medio nutritivo disputado por una pluralidad de fuerzas. Porque, de hecho, no hay 'medio', no hay campo de fuerzas o de batalla. No hay cantidad de realidad, cualquier realidad ya es cantidad de fuerza. Únicamente cantidades de fuerza, «en relación de tensión» unas con otras ${ }^{22}$. Cualquier fuerza se halla en relación con otras, para obedecer o para mandar. Lo que define a un cuerpo es esta relación entre fuerzas dominantes y fuerzas dominadas. Cualquier relación de fuerzas constituye un cuerpo: químico, biológico, social, político. Dos fuerzas cualesquiera, desiguales, constituyen un cuerpo a partir del momento en que entran en relación: por eso el cuerpo es siempre fruto del azar, en el sentido nietzscheano, y aparece siempre como la cosa más 'sorprendente', mucho más sorprendente realmente que la conciencia y el espíritu". ${ }^{23}$
\end{abstract}

No hay que entender el campo o el medio como algo previo a las fuerzas. Cuerpo no es lo que ocupa un lugar en el espacio. No se trata de un lugar o de un escenario previamente constituido donde la relación de fuerzas tendría lugar. Son las relaciones de fuerzas las que crean el medio o el escenario. Las fuerzas crean el ámbito que necesitan. Cuando se da prioridad al campo o al medio la resolución del conflicto entre las fuerzas se traslada al contexto de la relación, a la totalidad que contendría a las fuerzas (a la manera del estructuralfuncionalismo). El escenario o la totalidad es un resultado parcial, contingente y provisorio de las relaciones entre las fuerzas. Definición de cuerpo: allí donde hay al menos dos fuerzas en relación. ¿De qué ámbito? ¿De qué tipo? De cualquier tipo, de cualquier ámbito: químico, físico, social, político etc. En física se ha diferenciado entre los cuerpos y la energía, las ondas. Para Deleuze no hay escisión: cuerpo es energía, es una relación de fuerzas/energías.

Un cuerpo no se define por lo que es, sino por lo que puede; esto ya es un quantum de fuerzas en relación. No podemos definir de antemano lo que un cuerpo puede, de lo que un cuerpo es capaz dado que depende de las relaciones de fuerzas que lo constituyen, de la capacidad de afectar y ser afectado, de multiplicar y crear conexiones y relaciones nuevas, de aumentar o no su capacidad de actuar. Pero en un cuerpo, sostiene Deleuze, sólo se actualiza una porción de su poder. Un cuerpo deviene junto a otros cuerpos produciendo, afirmando relaciones,

\footnotetext{
${ }^{22}$ Nietzsche, F., La voluntad de poder, II, 373.

${ }^{23}$ DELEUZE, GILLES, NP, p. 60-61.
} 


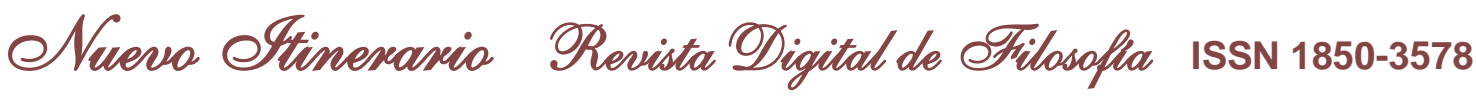
2013 - Vol. 8 - Número VIII - Resistencia, Chaco, Argentina. Pp. 39 - 57

encuentros y conexiones; afirmando diferencialmente su poder, su ritmo singular de cambio. Un cuerpo es un proceso abierto y en formación continua, oscilante, que des-estructura toda forma a priori de fundamentación. Por todo ello es que afirma Deleuze, "no sabemos de lo que un cuerpo es capaz". ${ }^{24}$ Un cuerpo es un flujo constante de fuerzas diferentes en relación disfuncional con otros cuerpos, pero siempre es una totalidad inacabada e incompleta. Por ello no es posible delimitar, definir, identificar de antemano qué es un cuerpo. El cuerpo se sustrae a los límites del pensamiento representativo, dado que un cuerpo es siempre posibilidad de realizar diferencias siempre nuevas, pero un cuerpo siempre es más de lo que realiza, es un campo de fuerzas generativas y productivas, como se dijo más arriba, actualizándose sin agotar su poder de cambio. Ahora bien, la diferencia entre las fuerzas se llama "jerarquía". Todo cuerpo es una relación de fuerzas desiguales, es decir, jerárquicas. ${ }^{25}$

\footnotetext{
"Las fuerzas inferiores se definen como reactivas: no pierden nada de su fuerza, de su cantidad de fuerza, la ejercen asegurando los mecanismos y las finalidades, ocupándose de las condiciones de vida y de las funciones, las tareas de conservación, de adaptación y de utilidad. Este es el punto de partida del concepto de reacción" ${ }^{26}$.
}

Las fuerzas reactivas se definen por su función o fin: conservar, adaptar, utilizar. Las fuerzas reactivas están siempre reguladas: siguen una regla, una ley, un límite, un impedimento. Lo reactivo se define desde el otro término de la relación, es decir, desde lo activo. Por eso las fuerzas reactivas parten siempre del límite, del impedimento, de lo que no se puede. Pero Deleuze advierte:

\begin{abstract}
“Indudablemente caracterizar a estas fuerzas activas es más difícil. Ya que, por naturaleza, escapan a la conciencia $^{27}$ : 'La gran actividad principal es inconsciente ${ }^{28}$. La conciencia expresa solamente la relación de algunas fuerzas reactivas con las fuerzas activas que las dominan. La conciencia es esencialmente
\end{abstract}

\footnotetext{
${ }^{24}$ DELEUZE, GILLES, NP, p. 62.

${ }^{25}$ ETCHEGARAY, Ricardo et Alia, La rebelión de los cuerpos, San Justo; Unlam, 2012, p. 234.

${ }^{26}$ DELEUZE, GILLES, NP, p. 61.

${ }^{27}$ Lo activo se identifica con lo inconciente. Por eso no puede conocerse o comprenderse desde la conciencia. Las fuerzas activas escapan a la conciencia.

${ }^{28}$ Nietzsche, F., La voluntad de poder, II, 227 [citado por Deleuze].
} 
reactiva ${ }^{29}$; por eso no sabemos lo que puede un cuerpo, de qué actividad es capaz"$^{30}$.

La conciencia ${ }^{31}$ es vista como un síntoma del cuerpo y no como su fundamento. Tomarla como síntoma es tomarla como efecto y no como causa. El síntoma no tiene que ser confundido con la causa. La conciencia es una mera superficie: aquella parte del cuerpo que se ve afectada por el mundo. Es un epifenómeno. Lo que le interesa remarcar a Deleuze es que la relación de la conciencia con lo exterior es siempre una relación entre dos fuerzas desiguales: una inferior y otra superior. La misma relación supone dos valoraciones, de acuerdo a la perspectiva de las fuerzas dominadas o a la de las fuerzas dominantes. La primera es la moral de los esclavos; la segunda es la moral de los señores. Los esclavos valoran partiendo del límite, de la ley, de lo que regula o impide. La conciencia parte de lo que no puede. Los señores valoran partiendo de lo que pueden. La valoración no está en la fuerza "en sí misma" sino en la relación que una fuerza establece con otras. Por eso, el concepto de fuerza no sustituye el concepto de substancia. Para Aristóteles la relación es un accidente de la substancia; para Nietzsche la relación de fuerzas es lo que constituye el cuerpo. La conciencia siempre está en relación con lo no-conciente o con lo inconciente. Ése inconciente es el cuerpo. Lo inconciente es activo, creativo, productivo, transformador. Por ello afirma Deleuze que "La conciencia: testimonia únicamente 'la formación de un cuerpo superior ${ }^{32133}$

“'¿Qué es lo que es activo? Tender al poder'34. Apropiarse, apoderarse, subyugar, dominar, son los rasgos de la fuerza activa. Apropiarse quiere decir imponer formas, crear formas explotando las circunstancias ${ }^{351136}$.

Las fuerzas activas sostienen siempre una tensión, una lucha, un antagonismo. Tienden a, se dirigen a... Pero, aquello a lo que se dirigen no es una substancia o un ser. Se dirigen al poder. Lo que quiere la fuerza es más fuerza. Lo que quiere el poder es más poder. El poder no tiene

\footnotetext{
${ }^{29}$ Nietzsche, F., La gaya ciencia, 354 [citado por Deleuze].

${ }^{30}$ DELEUZE, GILLES, NP, p. 62.

${ }^{31}$ Recuérdese que la conciencia ha sido tomada como el fundamento desde Descartes. La existencia se fundamenta en el pensamiento, en la conciencia.

${ }^{32}$ Nietzsche, F., La voluntad de poder, II, 227 [citado por Deleuze].

${ }^{33}$ DELEUZE, GILLES, NP, p. 60.

${ }^{34}$ Nietzsche, F., La voluntad de poder, II, 43 [citado por Deleuze].

${ }^{35}$ Nietzsche, F., Más allá del bien y del mal, 259 y Nietzsche, F., La voluntad de poder, II, 63 [citado por Deleuze].

${ }^{36}$ DELEUZE, GILLES, NP, p. 63.
} 
Q Nueva Etinexaxio Revista Digital de OFilosofia ISSN 1850-3578 2013 - Vol. 8 - Número VIII - Resistencia, Chaco, Argentina. Pp. 39 - 57

que ser pensado como una cosa o un ser, ni como una propiedad de las cosas o de los sujetos, ni como una facultad, ni como el lugar que ocupan ciertos sujetos. "Tender al poder" es desarrollar ese poder, es desarrollar las fuerzas, es crear más fuerza. Lo que caracteriza a lo activo es la capacidad de crear, pero no de crear cosas sino de crearse a sí mismo, de potenciarse a sí mismo. Detrás de la concepción spinoziana (no sabemos lo que un cuerpo puede) está la concepción hobbesiana, y detrás de la concepción hobbesiana están las concepciones de Maquiavelo y Tucídides. Según Etchegaray todos estos autores piensan el poder como fuerza y no como substancia. ${ }^{37}$ De allí que para caracterizar a las fuerzas activas utilice verbos y no adjetivos: apropiarse, apoderarse, subyugar. Activo son las fuerzas positivas, las fuerzas superiores, las fuerzas creativas y transformadoras. Es el poder de transformación, es pura actividad. Pero afirma Deleuze:

\footnotetext{
“Pero cada vez que señalamos así la nobleza de la acción y su superioridad frente a la reacción, no debemos olvidar que la reacción designa un tipo de fuerzas del mismo modo que la acción: sencillamente, las reacciones no pueden captarse, ni comprenderse científicamente como fuerzas, si no las relacionamos con las fuerzas superiores que son precisamente de otro tipo. Reactivo es una cualidad original de la fuerza, pero que sólo puede ser interpretada como tal en relación con lo activo, a partir de lo activo" ${ }^{38}$.
}

Se trata de fuerzas en relación, no de relaciones entre cosas o propiedades de una substancia o un sujeto. Deleuze tiene presente la teoría del poder de Foucault ${ }^{39}$ : el poder no es una propiedad, no es un lugar, no es una cosa, no es un atributo. No se tiene poder; se ejerce poder, se actúa. Toda fuerza es un ejercicio del poder. Toda fuerza es, por definición, poder. No existe una fuerza carente de poder. Una fuerza activa es aquella que hace todo lo que puede, lleva su fuerza al límite de lo que puede. Una fuerza reactiva nunca hace todo lo que puede, no lleva la fuerza al límite sino que parte del límite. Foucault no habla de fuerzas reactivas sino de resistencias. No hay poder sin resistencia. Se trata siempre de una relación, el poder es relación. Pero una incapacidad de lo reactivo para comprenderse a sí mismo más allá de su propio horizonte, que es el horizonte de la reacción, de la supervivencia. Aparece aquí una tesis central en la interpretación de Deleuze: no hay posibilidad que se den dos fuerzas

\footnotetext{
${ }^{37}$ ETCHEGARAY, Ricardo et Alia, La rebelión de los cuerpos, San Justo; Unlam, 2012, p. 227.

${ }^{38}$ DELEUZE, GILLES, NP, p. 63.

${ }^{39}$ Cf. DELEUZE, GILLES, Foucault, Buenos Aires, Paidós, 1987, pp. 49 ss.
} 
Q Nueva Etinexaxio Revista Digital de OFilosofia ISSN 1850-3578 2013 - Vol. 8 - Número VIII - Resistencia, Chaco, Argentina. Pp. 39 - 57

iguales. Es imposible eliminar las diferencias. Toda postura democrática, igualitaria, equivalencial es imposible. Para Deleuze, éste es el sueño de las fuerzas reactivas. El problema no es la igualación de las fuerzas sino la reactivación de las fuerzas, que las fuerzas activas se conviertan en reactivas. El problema es lo que Nietzsche llamó nihilismo. ${ }^{40}$

En definitiva, contra los dualismos metafísicos apariencia-realidad, sensible-inteligible, etc. y la pretensión filosófica de llegar a través de un método a fundamentos últimos y verdades absolutas, Deleuze vía la filosofía de Nietzsche propone una nueva praxis filosófica caracterizada como crítica genealógica, cuyos elementos decisivos son las nociones de sentido y valor que permiten evaluar las fuerzas en juego que se apoderan y conforman un cuerpo; de allí la relevancia genealógica de las preguntas ¿Qué quiere quien pretende establecer tal o cual verdad como absoluta y universal?, ¿qué fuerzas están de tras de ella?, porque para Nietzsche y Deleuze el pensamiento está siempre condicionado y determinado por relaciones de fuerzas como ya hemos expuesto. La voluntad de poder es la que determina la fuerza. El sentido y el valor derivan de la voluntad de poder como relación diferencial de fuerzas. La voluntad de poder es así principio de la síntesis de fuerzas, que no subsume al modo dialéctico sino que afirma la diferencia al establecer jerarquías. Pero para que esta síntesis pueda realizarse requiere de otro elemento relevante de la filosofía nietzscheana: el eterno retorno.

\section{Conclusión. La inmanencia. "El eterno retorno de la diferencia".}

El ser es comprendido por Deleuze como devenir de diferencia de fuerzas intensivas que se muestran y fluyen sobre un plano de consistencia. Ella es una diferencia que se rehúsa a toda conceptualización, especificación o limitación categorial. Aquí lo diferente se relaciona con lo diferente sin que pueda ser reducido a la identidad que opera en toda lógica de oposición. Esta es una diferencia móvil, que potencia y crea lo diferente, en cuanto diferente. Estas diferencias tienen como elemento decisivo la intensidad: puro movimiento diferencial de fuerzas que se multiplican al infinito. Esto implica, a su vez, concebir la diferencia como pura positividad, ello

\footnotetext{
40 "Según Nietzsche, el nihilismo es el lógico punto final de la filosofía Occidental. La filosofía comienza con un proyecto de vida del ascetismo: el renunciar al deseo por algún mundo más alto o mejor (como el mundo de la verdad). Nos imaginamos un mundo más verdadero y mejor más allá de apariencias. Cuando fallamos en comprender aquel mundo verdadero nos caemos en la desesperación o el nihilismo, ya que hemos perdido aquel mundo más alto que nosotros nunca tuvimos. La consecuencia es el resentimiento. Todavía sentimos la pérdida de algún mundo más alto o mejor, y entonces nos imaginamos culpables, castigados o excluidos. Esto alcanza su culminación con el cristianismo donde somos permanentemente culpables en un mundo irredimiblemente caído. Para Nietzsche, la respuesta apropiada a esta caída en el nihilismo, la decadencia y el resentimiento no consiste en encontrar otra base de verdad, sino en abandonar nuestra esclavitud a la verdad. Tenemos que tener la fuerza y el coraje para vivir con este mundo aquí y ahora" (COLEBROOK, C., Gilles Deleuze, Londres-Nueva York, Routledge, 2002, p. 19).
} 
Q Nueve Otinenaxio Revista Digital de Prilosofla ISSN 1850-3578 2013 - Vol. 8 - Número VIII - Resistencia, Chaco, Argentina. Pp. 39 - 57

sugiere un proceso de permanente diferenciación, sin puntos de referencia o fundamentos últimos. Esta diferencia de fuerzas intensivas no puede ser definida o reducida, desde una instancia exterior a ella, porque no hay exterior, el devenir, es-y-diferencia. Esto es lo que llamamos "plano de consistencia", ${ }^{41}$ necesario para quebrantar los límites fijos, que operan en la metafísica considerada como onto-teo-lógica. ${ }^{42}$ Consecuentemente, ello nos obliga a desfundamentar al sujeto y al objeto de su carácter trascendental y, a su vez, nos obliga a dejar de pensar la diferencia a partir de un fundamento organizador. Desde la consideración del ser como devenir que diferencia activamente, el movimiento "es" flujo caótico, abierto, que desfundamenta lo real. Pero ¿qué es la consistencia? La consistencia es el campo de fuerzas generativas y productivas que, constantemente, se actualizan en multiplicidades sin agotar su poder de cambio e impidiendo toda fundamentación. El plano de inmanencia o plano de consistencia es un todo ilimitado que se presenta siempre abierto pero que no totaliza sus partes en una unidad superior y absoluta dado que este plano mienta un sistema de coordenadas, de diferentes dimensiones y orientaciones que producen constantemente conexiones que renuevan, a la vez, la totalidad del plano. El plano de inmanencia o consistencia es un plano que se forja de dos caras: una comprende al ser (en tanto devenir), la otra refiere al pensamiento (el concepto). El concepto expresa las líneas de fuerzas y tensiones, los límites y las variaciones que constituyen al plano. Ello implica que no haya esencias trascendentes sino entrecruzamientos (encuentros y desencuentros, conexiones y desconexiones) de fuerzas. El concepto es una singularidad que sintetiza intensidades diferenciales y no abstracciones. En el concepto no hay totalizaciones universales 0 trascendentales sino conexiones o series conjuntivas $(y \ldots . . . . y . . . y) .^{43}$

\footnotetext{
${ }^{41}$ Debemos aclarar que el plano de inmanencia o plano de consistencia no refiere a un concepto porque esto implicaría que los demás conceptos del plano sean totalizados o fundamentados por esta suerte de concepto superior, universal, absoluto y necesario al que se podría llegar a través de una deducción (propia de la tradición filosófica) lo que permitiría, en definitiva, el cierre total del campo, y así estaríamos nuevamente ante la presencia de un fundamento absoluto al modo onto-teo-lógico de la metafísica occidental; pero ello es justamente lo que combate la filosofía deleuziana.

${ }^{42}$ Cfr. Sufra, nota $\mathrm{N}^{\circ} 4$.

${ }^{43}$ Recordemos que para Deleuze pensar es crear-conectar conceptos y este es el movimiento propio en donde se produce la actividad filosófica; pero el plano no preexiste a los conceptos sino que a la vez que se crean los conceptos, las conexiones intensivas, se constituye el plano como receptáculo conceptual que es el medio para toda creación y conexión posible. En definitiva el pensamiento se ex-pone en el plano a la vez que experimenta creando conceptos. Esto significa que hay simultáneamente pensamiento (sentido) y ser (voluntad) y que por un lado se distribuye (el plano) como realidad y por otro se interpreta como sentido-pensamiento. Es decir, el pensamiento es inseparable del ser y el ser mismo es inseparable del devenir de la vida.
} 
"Un pensamiento que fuese hasta el final de lo que puede la vida, un pensamiento que llevase a la vida hasta el final de lo que puede. En lugar de un conocimiento que se opone a la vida, establecer un pensamiento que afirmaría la vida. La vida sería la fuerza activa del pensamiento, pero el pensamiento el poder afirmativo de la vida (...). Pensar significaría: descubrir, inventar nuevas posibilidades de vida”. ${ }^{44}$

Conforme a la interpretación que Deleuze hace de Nietzsche pensar es inventar nuevas posibilidades de vida, nuevas formas de sentido. Como hemos analizado en el apartado anterior, hay formas de vida que la exaltan y potencian, y otras formas que la aprisionan y depotencian. En la inmanencia de la vida, en sus fuerzas es que se sitúa el elemento que permite evaluar las diferentes formas de vida y pensamiento. No hay verdades absolutas, mas allá del criterio que reside en la vida misma, sea esta noble o vil. Son estas fuerzas vitales las que permiten evaluar una vida como noble: fuerte creadora, o mezquina: Ilena de resentimiento y envidia. El peligro que ha acechado y acecha a la inmanencia de la vida es atribuir esta a alguna cosa, v. g., al espíritu, a la substancia, etc. Ello implica la constitución de universales abstractos o trascendentales propios de la tradición filosófica que se apropian del movimiento, lo detienen y atrapan para ponerlo a disposición (objetividad del concepto). Detener el movimiento implica negar el devenir de la vida. La inmanencia de la vida refiere a la potencia con la que el ser se alza contra la nada instituyendo al devenir mismo como la actividad inmanente al ser. Así Mengue define la inmanencia como "el encuentro de múltiples dimensiones o líneas de fuerza que se entrecruzan sin que una se eleve para cumplir el rol de unidad trascendente. La inmanencia reconduce al pluralismo". ${ }^{45}$ De este modo, la realidad (el mundo) aparece sobre un plano inmanente de múltiples dimensiones. La filosofía es experimentar, sostiene Deleuze, para liberar las fuerzas vitales de todo aquello que tienda a conservarla y aprisionarla, porque la vida es devenir, flujo que siempre retorna.

Pero debemos preguntarnos ¿Cuál es el ser del devenir? Deleuze nos da la respuesta "Retornar es el ser de lo que deviene. Retornar es el ser del mismo devenir, el ser que se afirma en el devenir. El eterno retorno como ley del devenir", ${ }^{46}$ y en su obra sobre Nietzsche afirma también:

\footnotetext{
${ }^{44}$ DELEUZE, GILLES, NP, p. 115.

${ }^{45}$ MENGUE, Philippe, Deleuze o el sistema de lo múltiple, Las cuarenta, Bs. As., 2008, p. 72.

${ }^{46}$ DELEUZE, GILLES, NP, p. 39.
} 
Q Nueva Etinexaxio Revista Digital de OFilosofia ISSN 1850-3578 2013 - Vol. 8 - Número VIII - Resistencia, Chaco, Argentina. Pp. 39 - 57

“El eterno retorno, según Nietzsche, no es de ningún modo un pensamiento de lo idéntico, sino un pensamiento sintético, pensamiento de lo absolutamente diferente que reclama un principio nuevo fuera de la ciencia. Este principio es el de la reproducción de lo diverso como tal, el de la repetición de la diferencia". ${ }^{47}$

De este modo, Deleuze comprende al retorno como repetición pero no como repetición de lo mismo, de lo idéntico sino que la repetición es de lo diferente de la diferencia, esto es, repetición de la posibilidad de relaciones, conexiones de fuerzas y multiplicidades siempre nuevas y diferentes. No es el ser el que retorna, el que vuelve, sino que es el propio retornar el que constituye al ser en cuanto se afirma en el devenir, y ello sucede eternamente. "No vuelve lo uno, sino que el propio volver es lo uno que se afirma en lo diverso o en lo múltiple" ${ }^{48}$

“El eterno retorno no es la permanencia del mismo, el estado del equilibrio ni la morada de lo idéntico. En el eterno retorno, no es lo mismo o lo uno que retornan, sino que el propio retorno es lo uno que se dice únicamente de lo diverso y de lo que difiere". ${ }^{49}$

El eterno retorno introduce, en el pensamiento deleuziano vía la filosofía nietzscheana, la noción de tiempo y le brinda una importancia capital al instante. Escuchemos sus palabras al respecto:

"el eterno retorno debe pensarse como una síntesis: síntesis del tiempo y sus dimensiones, síntesis de lo diverso y de su reproducción, síntesis del devenir y del ser que se afirma en el devenir, síntesis de la doble afirmación". ${ }^{50}$

Es decir que en el retornar mismo es el que sintetiza pasado, presente y futuro en el instante como plena afirmación del ser que en su retornar difiere produciendo la múltiple dimensionalidad de multiplicidades y al plano de inmanencia mismo a un mismo tiempo y de un solo golpe, de una sola tirada de dados, poniendo al azar como único principio del devenir. En definitiva, a partir de la noción de eterno retorno, entonces, se aborda definitivamente desde la filosofía al tiempo en su dinamismo constitutivo y se acaba con las nociones estáticas

\footnotetext{
${ }^{47}$ DELEUZE, GILLES, NP, p. 69.

${ }^{48}$ DELEUZE, GILLES, NP, p. 72.

${ }^{49}$ DELEUZE, GILLES, NP, p. 69.

${ }^{50}$ DELEUZE, GILLES, NP, p. 72.
} 
QNueva Etinexaxia Revista Digital de OFilosofia ISSN 1850-3578 2013 - Vol. 8 - Número VIII - Resistencia, Chaco, Argentina. Pp. 39 - 57

y abstractas de pasado, presente y futuro. Si lo que retorna es la diferencia, esto implica que no hay sustancia, ni unidad fundamental, ni identidades de antemano. El mundo es un constante fluir de diferencias intensivas (fuerzas). El eterno retorno es la potencia del ser del devenir que pone en relación una fuerza con cualquier otra. Lo que retorna es siempre lo que difiere. En conclusión, aparece aquí, entonces, una nueva ontología donde el ser es concebido como devenir, en cuanto que toda fuerza se relaciona con otras fuerzas diferentes, no regidas por un fundamento o principio totalizador al modo onto-teo-lógico. 